\section{Is there a place for animal experiments?}

\section{Kevin Dolan}

\section{The relevance of ethics in the controversy about animal use is unquestionable}

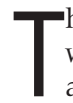
he conflicting arguments associated with the ethical aspect of the use of animals in research tend to centre on animal suffering and the benefits accruing from animal experimentation. The assessment of these two propositions as valid premises for relevant arguments is a salient feature in the ethical discussion on the use of animals in experiments.

The relevance of ethics in the controversy about animal use is unquestionable. It is significant that one of the prominent animal rights groups commandeers for itself the title "People for the Ethical Treatment of Animals (PETA)" (my italics).

We may have hard choices to make but they are not impossible; there are moral grounds, acceptable to many, justifying what we do. This is true of a far from insignificant proportion of the public (perhaps the silent majority) even if what is done may involve the possible suffering of an animal. Just as the majority appear to tolerate, at least tacitly, the slaughter of animals for enhanced cuisine, I would suggest that a majority, not necessarily made up of the same individuals, do not regard hazards to animals in the pursuit of sport as morally acceptable. The tolerance as regards the injuries to animals in sport will be more varied according to personal preferences and the sport in question. The teleological approach of these ethical attitudes-that is, judging the rightness or wrongness of an action according to its purpose, why it is being done, is certainly widespread.

\section{CHOICE BETWEEN TWO EVILS}

The researcher in the field of biology is faced with the choice between using animals in experiments or not using every weapon in his/her armoury to diminish the overpowering reservoir of human and animal suffering. There is clear evidence from history that the use of animals in research has alleviated somewhat that universal burden of affliction. The resulting benefits span the millennia and are still being achieved in animal units throughout the world. Other benign effective factors in the advancement of medical science, such as "in vitro" research and public health schemes, it must be acknowledged, have also played an important part in this progress.

In the dialectics regarding the use of animals in research the ethical dilemma brings into the frame the classic moral principle of the choice between two evils. It is taken for granted that causing animals to suffer is undesirable, in moral terms an evil. Set against this evil of animal suffering is ubiquitous affliction of living things-painfully obvious within the experience of all. This universality of pain is epitomised in the words of Francis Thompson; "Nothing begins, and nothing ends, That is not paid with moan; For we are born in other's pain, And perish in our own" (Daisy).

There is no doubt that as intelligent creatures we can do something about reducing that evil, the ever present possibility of misery for some poor creature or other. Indeed, a long line of scientists since the distant past have progressed knowledge so that some of that human and animal suffering has been alleviated; sometimes, of course, by the use of animals.

Many would rightly recoil in horror at the account of one of the very early recorded animal experiments in the West. The Greek, Alcmaeon of Croton (about $450 \mathrm{BC}$ ) recorded that he discovered the function of the optic nerve in a living animal by cutting through nerve fibre and noting the resulting blindness. The usefulness of such an experiment might appear as suspect to many.'

On the other hand, the history of medicine is strewn with examples of less traumatic and more acceptable use of animals in research which have definitely advanced the practice of the medical sciences. ${ }^{2}$

In 1837 an Irishman, Dr S L L Bigger, published a report describing his successful attempt at keratoplasty. While a prisoner of Bedouins in the Sahara desert he operated on a pet gazelle that had lost one eye from inflammation and developed scarring in the other eye from a wound of the cornea. He took a cornea from a wounded dying gazelle. Adhesion took place and 10 days after the operation the pet gave unequivocal signs of vision and the upper part of the transplanted cornea remained perfectly transparent.

Soon after, in 1838 in New York, Richard Kissam, inspired by Bigger's report, with some success transplanted a cornea from a pig to the eye of a young Irishman, John Dunn. Unfortunately the cornea became opaque within 2 weeks. No doubt these groundwork experiments using animals contributed directly to the development of future successful corneal transplantations. ${ }^{3}$

\section{Animals may have rights but do all creatures have a right to safe medicines and remedies for disease?}

There is the ever present dilemma of choosing between the acknowledged evil of causing hurt to animals and what some would see as the evil of "walking by on the other side of the street," ignoring suffering, not using the talents we have to reduce it.

Animals may have rights but do all creatures have a right to safe medicines, remedies for disease, etc?

We by no means claim that the use of experimental animals is desirable but is there a case for saying it is acceptable? This may be granted by many if we choose to regard restricted animal suffering in research as a lesser evil than allowing a continuation of suffering which could be prevented by science. Such a decision is not a comfortable one. It has none of the self satisfaction of high moral righteousness. It may be following a line for which we do not particularly care. We realise regretfully that for us it is an acceptable compromise. So often this is true of real life-the least worst is the best. Our attitude may be confusing but so are facts. Reality is not black and white. It is rather an infinity of greys. Because this particular ethical approach is far from absolute there is certainly lacking the solid ring of the confident ethical opinion associated with the deontological approach. The deontological approach presumes an awareness of a moral obligation, an intuitive certainty about the rightness or wrongness of an action with scant concern for its purpose or the surrounding circumstances-a drawing of a line in the sand, "so far and no further." On the other hand, in the context of the teleological approach caution is inherent in making decisions based on consequences. Who can know the consequences of consequences or even the disbenefits of benefits? Judgments are therefore hesitantly formed on a case by case basis. Relevant details and circumstances need to be taken into account. It is all important to ask the right questions. In practice, in research 
this demands a meticulous consideration of the cost/benefit appraisal.

\section{COST/BENEFIT}

Most researchers are fully aware of the oft recurring mantra throughout animal experimentation-cost/benefit. The rationale of this ethical axiom in research stems from consequentialism, a salient feature of utilitarianism. This English moral philosophy was developed by John Stuart Mill and Jeremy Bentham. They expounded the notion that "the good," "the desirable" - the right way to act-is the way that brings the greatest happiness to the greatest number. The whole thrust of animal experimentation has been in that direction. For example, the use of animals by William Harvey when researching the circulation of the blood, because it greatly advanced medical science, has benefited since then millions of humans and animals alike. Harvey's own masterpiece De motu cordis et sanguinis in animalibus makes the case admirably.

\section{THE THREE Rs}

Unfortunately there are difficulties intrinsic to utilitarianism, there is the inherent danger of the tyranny of the majority. A more obvious dilemma arises as regards the application of the cost/ benefit principle from the very nature of utilitarianism itself. It is a hedonistic philosophy-that is, it regards pleasure as good and pain as evil. If pain is evil, can its infliction ever be justified within this hedonistic philosophy? From the behaviour of utilitarians it was obvious they did not regard pain as an absolute evil since they neither totally condemned the then criminal code nor espoused vegetarianism. They did however strive to alleviate the general misery of their day.

Accepting then this utilitarian approach as a justification for using the cost/benefit principle we must, in keeping with its hedonistic imperative, commit ourselves to the minimisation of any animal suffering involved in their use in research. This calls for a wholehearted embracing of the principle of the three Rs of Russell and Burch. We must ever strive to replace animals in research by "in vitro" rather than "in vivo" procedures whenever possible; reduce as much as possible the number of animals we need to use, by good statistics and design of experiments; and refine both our experimental methods and care of all laboratory animals to obviate as much suffering as possible; in short, replacement, reduction, and refinement.

\section{EMOTIVISM}

Emotionally, some may experience a dilemma in embracing the morality prompted by utilitarianism with its cold calculating "felicific calculus" (weighing meticulously the moral quantum of the deed) and its hint of low moral ground. Some may look for comfort in the older deontological ethical approach-basing their decisions on instinct. I am not going to define instinct, you know what I mean-acting according to one's feelings-following one's conscience (perchance a flexible friend). Academically this attitude to the rightness or wrongness of an action may be referred to as emotivism.

A gut reaction will decide where the line in the sand is to be drawn- "so far and no further." Many technicians and scientists within research will tolerate certain forms of research but on moral grounds hesitate to become involved in more invasive procedures. Likewise but even more so in the case of using different animal species, variable and more definite personal opinions are held, often with deep conviction. In the numerous discussion groups I have been involved in over the years I have witnessed heated exchanges on where the line might be drawn regarding both types of procedure and species of animals. Some, for example, would express deep concern about orbital bleeding - a procedure for obtaining blood samples-or the use of nonhuman primates. In the case of suspect procedures, acceptance is often contingent upon the presence or absence of competency and expertise on the part of the operator.

At the expense of literary symmetry I digress to comment more fully on ethical attitudes to the use of non-human primates. Our own domestic legislation, as well as European directives, has begun to reflect the growing ethical awareness of the need to seriously consider the acceptability of the use of these animals in research. Our Animals (Scientific Procedures) Act 1986, stipulated in section 5.6 that only with special permission could non-human primates be used in research. More recently, restriction on their use has become more stringent. Any application to use wild caught nonhuman primates or to use any nonhuman primates in procedures of substantial severity must be referred by the secretary of state to the Animal Procedures Committee. ${ }^{4}$ More recently in 2001 a new and detailed section (section 18c) has been introduced into the application form for a project licence. This is a questionnaire in depth demanding full justification for any use of non-human primates.

An insertion in the LASA Newsletter (Winter 1997) makes the point.

"Great apes have never been used under the 1986 Act as laboratory animals. In future the Government will not allow their use. It is felt that the cognitive and behavioural characteristics of these animals means it is unethical to treat them as expendable for research."
The European Commission has become more insistent that member states reflect more closely the increasing moral sensitivity of citizens to the special status of our primate relatives. A draft community statement on the use of primates has been issued reinforcing directives 92/65/EEC (the Belai Directive) and 86/609/EEC for the better protection of non-human primates in laboratories.

\section{Ambiguity of attitude to animals is found among the public at large}

On the ground, this heightened awareness on the part of European authorities of public feelings towards monkeys in research has had practical results. The Dutch government announced that it will stop research on chimpanzees at the Biomedical Research Centre in Rijswick, the only chimp research facility operating in Europe. ${ }^{5}$

The significance of non-human primate research, however, is still appreciated within science. The Wolfgang Primate Research Centre opened in early April 2001 at the Leipzig Zoo (Leipzig, Germany). The centre will house a total of 60 great apes, including chimpanzees, bonobos, gorillas, and orang-utans in enclosures designed to mimic their natural habitat. Zoo visitors will be able to watch through one way glass as the scientists perform experiments designed to test the animals' cognitive ability including intelligence, tool use, numerical skills, and social behaviour. ${ }^{6}$

It is the tacit acceptance of intelligence and other advanced faculties in monkeys, expressed in the last paragraph, that motivates the greater ethical concern about the use of these creatures in research. Such concern encircles the globe. In February 1999 the New Zealand parliament entertained moves to grant legal rights to chimpanzees and gorillas.?

\section{UNIVERSAL AMBIGUITY}

Ambiguity of attitude to animals is found among the public at large on a wide canvas. Those who delight to ride to hounds properly vested might be horrified by the raucous atmosphere of the bull ring. In such cases the mores of the accepted culture, even in the same country, may vary and is of course greatly influenced by emotional reactions. The young aristocrat blooded at his first fox hunt is certainly emotionally programmed in a different way towards animals from a youth who has only known animals as household pets. For most of us emotional reactions change and develop as our experiences vary and build up, but always it would seem that in relation to animals there remains 
ambiguity, a persistent dilemma between our feelings and our needs in relation to the animals in our life. Many of us mentally divorce the frolicking lamb from the Sunday joint, except, of course, those who are committed vegetarians. Even in our serious and impassionate legislation there is evidence of species elitism. Protected animal is a restrictive term. The special regard given to some animals in law may have a whiff of respect for public sensitivity and rightly so if consensus is to be maintained. In law definite lines need to be drawn. Wherever lines are drawn there will always be some who disagree.

Even the most dedicated and devoted animal lover cannot escape dilemmas. It is difficult to protect both the whale and the krill at the same time.

\section{SENTIMENT}

Besides the terms emotion and emotivism-the ethical theory which regards moral decisions as being based on emotional reactions-a more potent word, however, often enters the frame, sentiment. It is not a word that always sits comfortably on the tongue of a scientist but it certainly has a place in the real world. The relevance of sentiment in the human-animal relationship was eloquently put by Andrew Kenny in an article in the Spectator (29 June 1991). The closer the association is with an animal the more likely an emotional bond will be forged, the more sympathy will be aroused, and empathy established creating real dilemmas in the human-animal encounter. Whatever dilemmas arise in our own case between our feelings for the animal under our care and the task we may be committed to, let us not be tempted to dismiss our sentiments out of hand or ruthlessly suppress our better feelings. Emotions play an important part in the expression of our personality. The adage "The heart has reasons of which the head knows nothing" (Pensees IV, 277) was written not by some idealistic poet in the clouds but by a scientist who has given his name to a measure of air pressure in isolators-Pascal.

Most of all, it is in the polemics concerning animal use in research that sentiment comes into its own. In any controversy involving deeply held opinions rhetoric is more persuasive than logic. Logic employs reason in polemics. Rhetoric tends more to play on sentiment. In talks for or against animal experimentation a harangue on sick children or fluffy rabbits is much more persuasive than a philosophical exposition of the cost/benefit assessment. If you are dubious about the effectiveness of harnessing sentiment in argument attend a serious court case in a higher court where a jury needs to be convinced. In a very early classic case involving animal cruelty under English law in the 1820s Richard Martin (of Martin's law fame) rescued his case from defeat by bringing the abused donkey into court. The aroused feelings of the jury swung the case in his favour.

An ancient court room may seem far removed from a modern animal unit but ethical and emotional attitudes still remain a fundamental part of human nature. Circumstances will vary from time to time and from place to place but human-animal relationships are a serious matter that need careful consideration. We may be far from a universal agreement on the treatment and use of animals. This should not, however, inhibit us from expressing our opinions on the matter and seeking a consensus which would be acceptable to most thinking animal lovers and that, in my experience, includes technicians and scientists. In the controversy associated with our work reconciling the extremes is impossible. In solving relevant dilemmas either ethical or emotional, sentiment, however, must not be ignored because often the sentiment of the animal technician has been a dynamic force in the past for advancing animal care and welfare.

BrJ Ophthalmol 2002;86:5-7

\section{Author's affiliations}

K Dolan, Bioscientific Events Ltd, Kent, IEA, UK

\section{REFERENCES}

1 Hirschberg J. Alkmaion's Verdienst um die Augenkunde. Arch Ophthalmol 1921;105:129-33.

2 Barley JB. The ethics of animal experimentation. Dissertation. London: Middlesex University, 1997.

3 Albert DM, Edwards DD. History of ophthalmology. Oxford: Blackwell Science 1996.

4 Animal Procedures Committee Report 1996, p 3, n 23

5 Lab Animal Europe 2001; 1 (No 5):5.

6 Lab Animal Europe 2001; 1 (No 5):7.

7 Dolan K. Ethics, animals and science.

Oxford: Blackwell Science, 1999:276.

\section{Contributors please note:}

Communications from all countries except the UK and Republic of Ireland should be sent to Professor C Hoyt, Editor, British Journal of Ophthalmology, University of California, Department of Ophthalmology, 10 Kirkham Street, K 301, San Francisco, CA 94143-0730, USA (tel: 001415502 6871; fax: 001415514 1521).

Manuscripts from the UK and the Republic of Ireland should be sent to Professor Andrew Dick, UK Editor, British Journal of Ophthalmology, Division of Ophthalmology, Unversity of Bristol, Lower Maudlin Street, Bristol BS1 2LX (tel: +44 (0) 117929 4496; fax: +44 (0) 117929 4607). 